\title{
The Use of Reproductive Health Information Material in the Rural Clinics of Umtata District
}

\section{ND Mbananga \\ $\mathrm{MA}$}

Medical Research Council

\begin{abstract}
Though it appears that there has been a long history of development, distribution and dissemination of reproductive health information materials, impediments still exist in the health information, communication and education systems in South Africa. The aim of the study was to contribute towards improvement of the deve-lopment, distribution and utility of reproductive health information material both in the Eastern Cape province and nationally. In-depth understanding of complexities surrounding development, distribution and utility of educational material is key to the provision of information to communities.

The objectives were to describe the availability and examine the content, target groups, language and utility of reproductive health information materials. Qualitative study using non probability sampling was done. Ten rural clinics were conveniently selected. In-depth interviews, focus groups and a checklist were used to collect data.

Reproductive health information materials found were mostly posters, there were no pamphlets, material on some reproductive health aspects was not available, inconsistently distributed and not updated.

It was concluded that posters are available in the rural clinics of Umtata district judging from the results there is a need to improve the quality of reproductive health information material.
\end{abstract}

\section{INTRODUCTION}

information was barely sufficlent to display at clinics, and therefore, not serving its purpose of community education."

During the 1970s South Africa established an acute Family Planning Programme within the Department of National Health and Population Development(PDP). This programme became a strong vertical family planning service, which embarked on mass provision of contraception, while also running education, information and communication programmes, (Klugman 1993). Since this period, the National Department of Health together with some organisations have developed, distributed and disseminated family planning information materials to communities and clinics.

South African health services faced a critical review during the pre- and post election periods around 1994 . The concept of sexual and reproductive health was introduced in South Africa for the first time (WHO 1994). The inclusion of both sexual and reproductive health meant redefinition of demarcation lines. This definition suggested that traditional areas, such as maternal health and family planning, should be broadened to include safe abortion services, cervical screening programmes, STD and AIDS programmes and reproductive health rights, (WHO 1994). The extent to which this has been adopted by the health services is not clear.

The Health Department has a long history of dissemination of family planning information and more recently of disseminating STD/HIV/AIDS, information material.

However, it appears to have been few if any, studies describing the development, distribution, dissemination, comprehension and utilization of reproductive health information material. The reproductive health task force (WHO 1994), however, revealed problems with health education provided by health services. The task force found that nurses perceived that less value was attached to health information by their seniors, whom they felt were only interested in the number of 
contraceptives issued, rather than combining performance indicators and health promotion indicators. According to the report, some nurses had even stopped providing health education (WHO 1994). In another study among nurses in the Northern Province, Klugman(1993) identified a lack of knowledge around reproductive health by carers. Specific areas that were deficient were emergency contraception, treatment of rape victims and STD treatment (WHO 1994, Reproductive Health Task Force). These studies may be showing a glimpse of a bigger problem surrounding reproductive health information that is available to nurses and the community as consumers. They suggest that although the National Department of Health and other organisations develop, distribute and disseminate reproductive health information, some does not reach the providers of health education or the health education system is not coordinated. It may also show that the information is underdeveloped or lacking.

Mathews et al.(1998) conducted the study for a popular soap opera "Soul City" around health education. However, this study was done to assess the potential effectiveness of using audio visual presentations in the waiting rooms of South African primary health care clinics to educate patients about STD prevention and treatment.

Published literature revealed no studies that examine the process of the distribution, dissemination and availability of reproductive health information in rural clinics have been done in South Africa. It is not known what reproductive health information is available at these clinics, which organisations provide the information, how it came there or how clinic health workers(nurses) understand, interpret or utilise it for health education programmes in the communities they serve. Also little is known about how relevant reproductive health information is for communities who are the consumers of the information. Health workers are the gatekeepers of reproductive health information, therefore, their contribution would give an in-depth understanding around the development, distribution, dissemination and consumption of reproductive health information.

Literature show that there is comprehensive problems surrounding information in general. These problems are even worse if such information is developed out of popular culture of consumers and users. Also some forms of communicating information though popular are not easily understood by consumers (Sless 1981; Schlesinger 1978 \& Golding \&Philip
1976). The same literature suggests that these problems are minimised by use of surrogate consumers.

The study done by Mellanby (et al.; 1996) on sex education found that there was a problem in sex education content provided for students from rural, semi urban and urban schools of England.

However, it seems that there is little attention that has been given to the distribution, dissemination, nature and content of health promotion information in general. Studies tend to be on an individual outcome rather than on larger organisational issues, such as network analysis and the content of the message (Benton and McDonald 1992, Mealier et al 1996)

\section{AIM OF THE STUDY}

The aim of the study was to investigate availability and utility of reproductive health information materials in rural clinics. The information gathered will help to improve the processes of development, distribution, dissemination and management of reproductive health information material.

\section{Specific objectives are:}

1. To describe the availability of reproductive health information that is present in rural clinics of the Umtata district.

2. To examine the content of reproductive health information available at rural clinics of the Umtata district.

3. To identify target groups for reproductive health information in the rural clinics.

4. To investigate the extent and complexity of the language used in messages of reproductive health information.

5. To investigate how clinic health workers utilise reproductive health information materials.

\section{RESEARCH METHODS}

The Eastern Cape was chosen as a study area because it is mainly rural and has not been researched extensively. Furthermore, the Eastern Cape has a lot of scope for service improvement. The Umtata district was chosen as it falls in the most rural and under served part of the Eastern Cape. The population of three hundred thousand live mostly $(98 \%)$ in the rural areas (Transkei Census 1991). The study was done in ten conveniently selected clinics in the Umtata district.

\section{Study population}

The study was done in ten conveniently selected clinics in the Umtata district. Eight nurses were interviewed one in each of the eight clinics visited. In the two health centres visited focus groups of ten health workers each were conducted. Ten primary care health facilities were selected to expose the variations between clinics.

\section{Methodology}

Qualitative methods were used to gather data related to the distribution, availability and use of reproductive health information. Focus groups and semistructured interviews were engaged in the clinics to get more information on how health workers in rural clinics interpret, understand, disseminate and utilise reproductive health information. Photographs and observational methods were used for collecting data from posters hanging against the walls of the clinics. The study covered all reproductive health information available in the rural clinics, such as HIV, AIDS, sexually transmitted diseases (STDs), sexuality, reproductive cancers, and family planning information, such as posters and leaflets.

\section{Data collection}

An appraisal of available reproductive health material in each clinic was conducted. A checklist was completed for each reproductive health material that was found and photographs of available posters were taken in each rural clinic. For every clinic the information related to the type of material, the producer, source, target groups, the approximate age, language, condition and circumstances of the display of posters and storage of leaflets were entered onto checklists. Though this study is mainly based on qualitative methods, the data collected by use of a checklist provided minimal quantification.

As clinics differ in terms of size, service and staff, the researcher chose the appropriate method to interview staff. Where nurses were two, semi-structured to in-depth interviews were conducted and one nurse was interviewed. In health centres where there were more than ten nurses two focus groups were conducted, however, nurses had to alternate so that clients were not left unattended. The focus group sessions were preferably conducted during the lunch hour, and lasted about $\mathbf{4 5}$ minutes. Interviews and focus groups were conducted in Xhosa, the mother tongue of the researcher and the subjects.

The nurses in the smaller clinics, though only two, managed to spend more time on in-depth interviews because of the steady flow of patients compared with the health workers in health centres. Therefore, in-depth interviews were conducted in smaller clinics.

A tape recorder was used for both focus groups and the in-depth interviews with 
the permission of the participants. Notetaking was difficult as there was no regular assistance. Limited assistance was offered by one member from the information unit, as she saw it as an opportunity to learn and also visit clinics to collect monthly and quarterly statistics which is routinely sent to her office.

\section{Data analysis}

\section{Descriptive analysis}

All checklists were first counted for the total number of posters and reading materials available at all the clinics visited. This analysis indicated the distribution of posters and pamphlets to clinics. Secondly, the forms were counted according to each clinic to assess variation between clinics. Further descriptive analysis was done by looking at the type of material available at clinics, indicating the distribution variation by type. Analyses were done by theme and by clinic to examine distribution, inconsistency and flow of information. Language use of the materials was analysed by vernacular or foreign to assess language use and suitability of reproductive health information materials. Materials were examined by source to check distribution and development of those found. Posters were counted and grouped according to the developer or source and language used. The dates of issue or publishing were controlled for up-to-datedness of information available. The materials were analysed by target group to measure targeting. The quality and storage condition of materials were examined. Finally the materials were analysed by area of display and dissemination of information by type.

\section{Content analysis}

The tape-recorded data of interviews and group discussions were analysed by identifying themes and topics. Sources of posters, information needs, language suitability, poster communication, health education, information dissemination, and information construction were the themes identified. Data were first organised into broad themes and then confined to specific topics.

Validity and trustworthiness of data were maintained by keeping tapes recorded during focus groups, in-depth interviews and photographs of posters taken from clinics which would be made available to any researcher who might wish to analyse the data.

\section{ETHICAL CONSIDERATIONS}

The researcher approached the provincial health authorities for permission to undertake the study. Nurses in the selected rural clinics were informed of the study as the researcher approached relevant health offices during the planning phase of the study. At the clinic nurses received a consent form, which assured voluntary participation in the study. After reading the consent form the study was explained to them. Confidentiality of all information was ensured. Some reproductive health information materials from the National Department of Health and the district health office in Umtata were given to nurses in most clinics visited at the end of the interview or focus groups. Most health workers were interested and willing to participate in the study. The study was approved by ethics committee at the University of Witwatersrand.

\section{RESULTS \\ Reproductive health information material}

Distribution of posters did not show a correlation with the proximity to the urban area of Umtata, which was identified as the main source of supply of health information materials for all the clinics visited. The distances travelled to the clinics ranged from 10 to 70 kilometres from the urban area of the Umtata district. Three of the ten clinics are between 60 and 70 kilometres from the urban areas, while four clinics are within a radius of 20 to 45 kilometres, and the remaining 10 to 15 kilometres.

The total number of reproductive health posters found in the clinics was twentythree (23). On the average there were two posters in each clinic. Pamphlets and leaflets on reproductive health were not available in most clinics. Only one clinic had pamphlets on STDs that were in English and stored in a cupboard and, therefore, not in circulation due to the language problem.

\section{Display of posters}

The posters displayed against the walls were in good condition, and only two were found tatty. Posters were mostly displayed in the waiting rooms, and in many of the clinics in a way that they were not catching the eyes of patients and clients. The inappropriate display was mainly due to the design of clinics waiting rooms.

In some clinics space was a problem and it appeared impossible to display reproductive health information posters at suitable visible positions. There were also materials on TB, Extended Programme on Immunisation, breast feeding etc., that took up space.

Furthermore, materials from Water Affairs, Transport, Welfare and Agriculture Departments seemed to compete for space at the clinics visited. Because of these problems mentioned, health workers suggested that flip charts could display posters on a weekly basis or whenever necessary. The space problem at the clinics meant posters were removed from the walls whenever new ones arrived. The health workers found changing of posters time consuming and rather hazardous as they used ladders for this

Reproductive health information was barely sufficient to display at clinics, and therefore, not serving its purpose of community education. Only those people, who attended clinics had an opportunity to know anything about health information materials. Health workers believed that reproductive health information materials should be available to everybody and not only to clinic attendees. Posters should also be available at public centres like schools, churches, shops and against telephone and electricity posts like many adverts.

The producers of posters were identified by their organisation's name at the bottom of the poster. Producers that were identified were the various past and present government Departments of health and NGOs. They included:

1 The then National Department of Health and Population Development (NDHPD).

2 National Department of Health.

3 Population Development Programme (PDP) of the then Department of Welfare Transkei.

4 The then Department of Health Transkei.

5 AIDS unit Department of Health in Bisho.

6 Society for Family Health (SFH).

7 AIDS Helpline.

8 Lygnon ED.

9 Berfumed.

It was difficult to assess which communities were targeted by the posters, since they tended to be rather universal and messages were nonspecific. With the assistance of health workers it was concluded that most posters were targeting everybody. Two posters targeted teenagers. The variation of poster types and themes between clinics appeared to be greater than within clinics.

\section{Sources of information for rural clinics}

The information that reached the clinics was mainly supplied by the Umtata General Hospital community centre. Health workers received most of the posters when attending meetings or at in-service training at the Umtata Hospital Sometimes the health information materials were provided on request but usually when the materials became 
available. Posters were not delivered to clinics. There was no system for health workers to order any health information material. They did not know how or where to order information material. They accepted what was given to them by the hospital and never asked what was available or not, since they never knew what was supposed to be available. There was no catalogue at the clinics to assist them in ordering the information they wanted. On Only one instance a health worker had ordered diabetes information from a centre in Durban and Braamfontein. Aids co-ordinators were another soruce of reproductive health information.

Health workers did not have the opportunity to order reproductive health information, which in their opinion was needed for their communities. Health workers believed that the communities somehow differ, and that reproductive health information could be needed by one community, but not by others. Communities, to a limited extent, differ in terms of the prevalence of diseases, social class and literacy. Therefore, acquiring any type of information because it is supplied did not help their communities much.

Health workers would like to be provided with catalogues and centres where to obtain reproductive health information for ordering purposes. They never received enough materials from suppliers like Umtata Hospital to provide for their communities and especially the schools in their area.

Six themes were observed in the posters. AIDS awareness was covered by ten posters, while family planning by eleven. There was one poster on youth sexuality and two posters on condom use. No posters were available on STDs and reproductive cancers. No publishing date was noticed on any posters at the ten clinics. However, some of them must be several years old as they were produced by the former Departments of Health.

\section{Language and Culture}

Posters were mostly in English, a few in English and Xhosa, and others in English and Afrikaans. Most of the English posters were from the National Department of Health, FSH, Lygnon ED and Berfumed. The English and Xhosa posters were produced by the then Transkei Department of Health.

In some cases the language used in posters was too academic to be understood by communities. Health workers reported that sometimes the terminology was not easily translated to vernacular language. Though English posters were inappropriate, they could be bilingual in most cases, e.g. Xhosa and English. Health workers reported that English posters were not helpful for illiterate communities. Health workers felt that in some instances reproductive health language, which was used in the posters available, was very sensitive when translated into Xhosa.

Some posters and pamphlets did not consider the cultural aspects of communities. In some instances these posters did not consider the norms and values of the communities. In most communities that are served by these, it is taboo to call reproductive organs by their real names.

Communities could consider this as vulgar and unprofessional. Development and conceptual development of reproductive posters should be culturally based and should reflect local reality, e.g. posters with kraals and thatched huts would be better understood by communities. Health workers felt that most reproductive health posters were too abstract, very urbanised and in some cases did not make sense to local communities. Most people did not ask questions about posters.

Health workers reported that posters on women's reproductive organs were a source humiliation to men, who closed their eyes when showed the female reproductive organs. Women also turned their eyes away from the posters on male reproductive organs. In other words such posters did not provide any form of education for communities, but were a source of embarrassment.

Health workers believe that explicit posters should be reserved for school pupils and not for the older generation in the communities that the health workers are serving. Reproductive health information development should be sensitive to the communities' attitudes. The construction of reproductive health information material should consider local language that is accepted by communities. "There is always a local acceptable language, which is usually known by many people in an area, that is why posters should be developed locally" one nurse said.

Posters that were available on reproductive health were meaningful to health workers and they understood the messages. Most posters, however, did not communicate much. In some instances there was a great deal of irrelevance between the words and the picture on the poster that they might be conveying.

Health workers were of opinion that a poster should not need words to communicate a message. Pictures should be self reliant in passing messages to communities. Posters on clinic walls should speak for themselves, especially for the illiterate who cannot read what the words are explaining on an unclear poster. For example, a poster on female reproductive organs bears no meaning to an illiterate woman, because she does not know what the uterus looks like, unless they are first taught that " this is how the cervix looks like" one health worker explained.

\section{DISCUSSION}

The results show that there is no correlation between the proximity of the supplier and the availability of reproductive health information to rural clinics. It also appears that posters are widely distributed as compared to pamphlets and leaflets on reproductive health information materials. The results show that posters are widely distributed and are in line with the study done that states photographic information though problematic plays a major role in education (Sless 1981). These results also reveal that requisitioning of reproductive health information is grossly unbalanced. More family planning and AIDS awareness information are distributed than STDs and reproductive cancers. This has an impact on the flow of information to target communities.

Another important discovery of the study is a greater variation of information between clinics than within clinics.

Variations of themes covered by reproductive health information materials between and within clinics show some degree of inconsistency in the flow of information to communities. While it is possible that different clinics have needs in reproductive health information material, there was no evidence to suggest that this was the consequence deliberate strategy. Again this is a point on the distribution and flow of information to target communities. The results reveal that unorganised distribution of health information materials on reproductive health will result in redundancy and confusion in the flow of information as messages from different producers tended to contradict.

The study shows that development of health information materials on reproductive health has no publishing dates. This alone shows that construction of reproductive health materials is not updated and therefore, again faced with redundancy and is out of context in terms of the information needs of communities. The use of mainly English in the materials distributed on reproductive health shows the ignorance of the developers to their audience. If they are not ignorant, they 
are not sensitive to the audience. The study indicates that the concept of an inferred audience is valuable if posters and their messages are aiming at effective communication. The inferred audience is sometimes a necessary guide in the construction of messages, particularly in the use of language (Gelding 1976; Schlesinger 1978).

Health workers reported that their clients seemed not to be interested in posters that were displayed. For health workers this lack of interest is attributed to the sophistication of pictures and poor communication on the part of the reproductive posters.

Health workers' views of posters for being too abstract and urbanised may be coming from the general view that visual communication is a major transmitter of cultural heritage. People tend to understand what is familiar to their environment. From a socialisation stance the message on the poster becomes far more removed from the audience that it becomes problematic, because each generation must regenerate concepts, which they understand well (Sless 1981).

Therefore, posters are generated by another generation for other generations. Generation in this particular case refers to different communities, which share different values, norms and conceptual background. Communities that develop posters are differeni from the consumer who are communities in this particular case. Pictures have definition because they have been endowed by individuals in a society or generation, who understand the concepts it developed. Posters do not have definition to consumers because they have to deal with concepts that they have not generated.

The supply of the information to rural clinics without considering the need of the particular community is another fact that cannot be disregarded in this study, as it could be linked to the insensitivity of producers and suppliers to the information needs of these communities. This insensitivity, detected by the study, reveals a logical imperative to construction of posters that does not serve much purpose if it is not consumed as expected.

The study illuminates that pictorial education, which takes place outside a popular culture is not good enough. Most people as reported by health workers do not bother about asking questions about posters. This may suggest that though people see pictures they do not think deeply about them. Another discovery is that posters are not simple and self evident as one would imagine. Most posters are supported by a lot of words to say something. It appears that without words communities and other users of posters would need graphic designers and developers to stand next to them and explain. Besides, lots of words on posters pose redundancy.

Health workers seem to be dissatisfied with the way they were supplied with the information. It appears that there was a problem in ordering sufficient quantities of reproductive health information by the source. The problem was twofold as the then Transkei Department of Health was no longer developing posters, and they depended on materials from AIDS coordinators. The source also does not have a systematic way of ordering the information that would enable adequate information supply for clinics. There is, however, a system of distribution which is based on meetings and in service training.

Though there is this type of information distribution, health workers want to order information themselves and not be supplied by the available source.

This is a reasonable demand, since health workers feel that they are sometimes supplied, to their opnion, with what is not suitable for their communities The study also shows there is a need for reproductive health information catalogues for health workers to order information on the basis of what is available.

Though health workers emphasized lack of understanding of posters between their clients and patients, it is not clear whether clients lack the necessary cognitive skills to affect the required transformation of posters. Health workers mentioned that clients would not be able to recognise a cervix on a poster unless they have been taught. However, the study does not clarify whether clients make errors at the level of transposition when recognising the pictures of reproductive health posters. It is hoped that further study will be able to give some clarity in this area.

The study suggests that a system of poster development needs to change and certain rules should be formalised in the process. Some questions should be asked, like what kind of information should be shown, what education point needs to be made, what will the consumers or target groups do with the information, and can previous posters be reproduced.

\section{CONCLUSION}

In conclusion reproductive health information for rural communities in the Eastern Cape is inconsistently distributed, poorly disseminated, insufficient too abstract, redundant, not updated, communicated in a foreign language, not self reliant to education, and lacks clarity. It is dominated by family planning and AIDS awareness and does not provide other reproductive health aspects such as reproductive cancers and STDs. More posters than pamphlets are distributed. Information does not have publishing dates. In summary, posters are available, but judging from the responses by health workers they are probably failing to communicate health messages.

\section{RECOMMENDATIONS FOR REPRODUCTIVE HEALTH INFORMATION}

Several recommendations are made for improving this type of service. These include the local development of reproductive health information which should be culturally based reflecting local reality. Sources and available reproductive health information material should be in catalogue form and available to nurses. An organised distribution of reproductive health information should be organised for rural clinics. The language of reproductive health information material should be acceptable to consumers. Reproductive health information should be disseminated in large quantities for wider distribution to consumers. Umtata area needs a clearance house. Reproductive health information materials should be in pamphlet and poster format. Reproductive health information material should cover a wide range of reproductive health problems. Reproductive health information material should have a publishing date. For major health issues such as AIDS new information should be provided all the time.

\section{ACKNOWLEDGEMENTS}

Sincere gratitude goes to Health Systems Trust for funding the study. The authorities of the Department of Health in the Eastern Cape are also acknow-ledged for permission to conduct this study. A special word of thanks goes to the nurses at the clinics visited in the Umtata district, $\mathrm{Dr}$ Bradshaw for the scientific guidance, Mrs $N$ Tutshana who assisted me in the field and Mrs $J$ Fourie for editing. Mrs E. Gerber's administrative support is greatly appreciated. 


\section{REFERENCES}

BUNTON, R. \& MACDONALD, G. 1992. Health promotion: disciplines and diversity. Routeledge : New York.

GolDING, P. \& PHILIP, E. 1976. Making the News. Centre for Mass Communication Research : University of Leicester.

FOLCH-LYON, E. LL, \& SCHEARER, S. 1981. Focus group and survey research on family planning in Mexico. Studies in Family planning, 12(12):409-432.

KLUGMAN B. 1993. Balancing means and ends - population policy in South Africa: Population and family planning policies: women centred approach. Reproductive Health Matters No. 1, May.

MATHEWS, C., ELLISON, G., GUTTMACHER, S., REISCH, N. \& GOLDSTEIN, S. Can audiovisual presentation be used to provide health education at primary health care facilities in South Africa. (Paper read at HEALTH SYSTEMS TRUST Annual Conference 1998).

MEILIER, L. K., LUND, A. B. \& KOK, G. 1996. Reactions to health education among men. Health Education Research 11(1), March.

MELLANBY, A. R., PHELPS, F. A., CREIGHTON, N. J., \& TRIP, J. H. 1996. School sex education, a process for evaluation: methodology and results. Health Education Research 11(2), June.

REPRODUCTIVE HEALTH TASK FORCE, SOUTH AFRICAN MINISTRY OF HEALTH WHO, HRP. 1994. Assessment of Reproductive Health Services in South Africa Focussing on Family Planning (Draft Report). Geneva.

SCHLESINGER P. 1978. Putting Reality Together. Constable : London

SLESS D. 1981. Learning and Visual Communication. Croom Helm Ltd : London.

TRANSKEI CENSUS. 1991. The Department of Commerce : Transkei.

WORLD HEALTH ORGANISATION. Health for All in the $21^{\text {st }}$ Century. Geneva

WORLD HEALTH ORGANIZATION. 1994. Family and Reproductive Health: Special Programme of Research. Development and Research Training in Human Reproductive Health. Geneva. 